\title{
Probable congenital SARS-CoV-2 infection in a neonate born to a woman with active SARS-CoV-2 infection
}

\author{
Maksim Kirtsman MDCM, Yenge Diambomba MD, Susan M. Poutanen MD MPH, Ann K. Malinowski MD, \\ Evangelia Vlachodimitropoulou MD PhD, W. Tony Parks MD, Laura Erdman MD PhD, Shaun K. Morris MD MPH, \\ Prakesh S. Shah MD MSc
}

Cite as: CMAJ 2020 June 15;192:E647-50. doi: 10.1503/cmaj.200821; early-released May 14, 2020

A 40-year-old woman (gravida 2, para 1) was admitted to a tertiary hospital in Toronto, Ontario. She had familial neutropenia, gestational diabetes and a history of frequent bacterial infections, including 3 episodes (sinusitis, skin infection and bronchitis) during this pregnancy, which resolved with antibiotic treatment. Details of the maternal course and outcome have been published separately because of her hematologic condition. ${ }^{1}$

The patient presented with myalgia, decreased appetite, fatigue, dry cough and temperature of $39^{\circ} \mathrm{C}$ in the preceding 24 hours. A nasopharyngeal swab was positive for suspected severe acute respiratory syndrome coronavirus 2 (SARS-CoV-2)gene targets via reverse transcription polymerase chain reaction (RT-PCR) testing (Allplex 2019-nCoV assay, Seegene). There were no fetal concerns during the pregnancy or following admission. The woman did not need any respiratory support at the time of birth. A semiurgent cesarean delivery was done under regional anesthesia, with airborne, droplet and contact precautions, owing to worsening coagulopathy (elevated D-dimer and fibrinogen levels, and elevated activated partial thromboplastin time) and reducing platelet count at 35 weeks and 5 days' gestation. Artificial rupture of membranes was performed at operation. The amniotic fluid was clear. The male neonate was vigorous and did not require resuscitation. His Apgar scores were 9 at 1 minute and 9 at 5 minutes, and his birth weight was $2.93 \mathrm{~kg}$.

In line with our local protocol, delayed cord clamping was not performed, and the neonate was immediately removed from the operative field, in a sterile fashion, to a resuscitator $2 \mathrm{~m}$ away in the same room. Placental swabs (both maternal and fetal sides) were obtained. Placental tissue was sent for PCR and histopathologic examination. Nasopharyngeal swabs were obtained from the neonate on the day of birth, day 2 and day 7 , after thorough cleansing of the baby and before contact with the mother.

All 3 of the neonate's nasopharyngeal swabs were positive for SARS-CoV-2 gene targets via RT-PCR testing; neonatal plasma tested positive on day 4, and stool was positive on day 7 . The results of the maternal and neonatal investigations, including

\section{KEY POINTS}

- Neonates born to women with confirmed or suspected severe acute respiratory syndrome coronavirus 2 (SARS-CoV-2) infection should have testing of the nasopharynx, placenta and cord blood as soon as possible after birth, after thorough cleaning of the neonate.

- Sample timing, collection methods and types of samples should be documented to help differentiate congenital, intrapartum and postpartum acquisition of SARS-CoV-2 infection in neonates.

SARS-CoV-2 PCR results using the Allplex 2019-nCoV assay, are presented in Appendix 1, Supplemental Table S1 (available at www. cmaj.ca/lookup/suppl/doi:10.1503/cmaj.200821/-/DC1). Detailed results including PCR cycle thresholds for specific PCR targets (envelope, RNA-dependent RNA polymerase and nucleocapsid genes) as an indirect measure of viral load are reported in Appendix 1, Supplemental Table S2.

Each of the 5 random sections of placenta showed multiple areas of infiltration by inflammatory cells and extensive early infarction. The inflammatory infiltrate consisted nearly entirely of CD68-positive macrophages. Only scattered T-cells (CD3), B-cells (CD20) and neutrophils (CD15) were identified on immunohistochemical examination. The inflammatory infiltrate was largely confined to the intervillous space, consistent with chronic histiocytic intervillositis. The histopathologic findings, however, differed from those of more typical cases of chronic histiocytic intervillositis in 2 important features: the widespread early infarction and the clustering of the inflammatory cells around the chorionic villi (Figure 1).

The woman and newborn were transferred to a negativepressure room on the postnatal ward. The woman attempted breastfeeding with appropriate precautions, including wearing a mask, practising appropriate hand and breast hygiene, and keeping the baby $2 \mathrm{~m}$ away from her between feedings. The neonate was noted to be neutropenic and had mild hypothermia (lowest temperature $35.9^{\circ} \mathrm{C}$ ), feeding difficulties and intermittent hypoglycemic episodes 


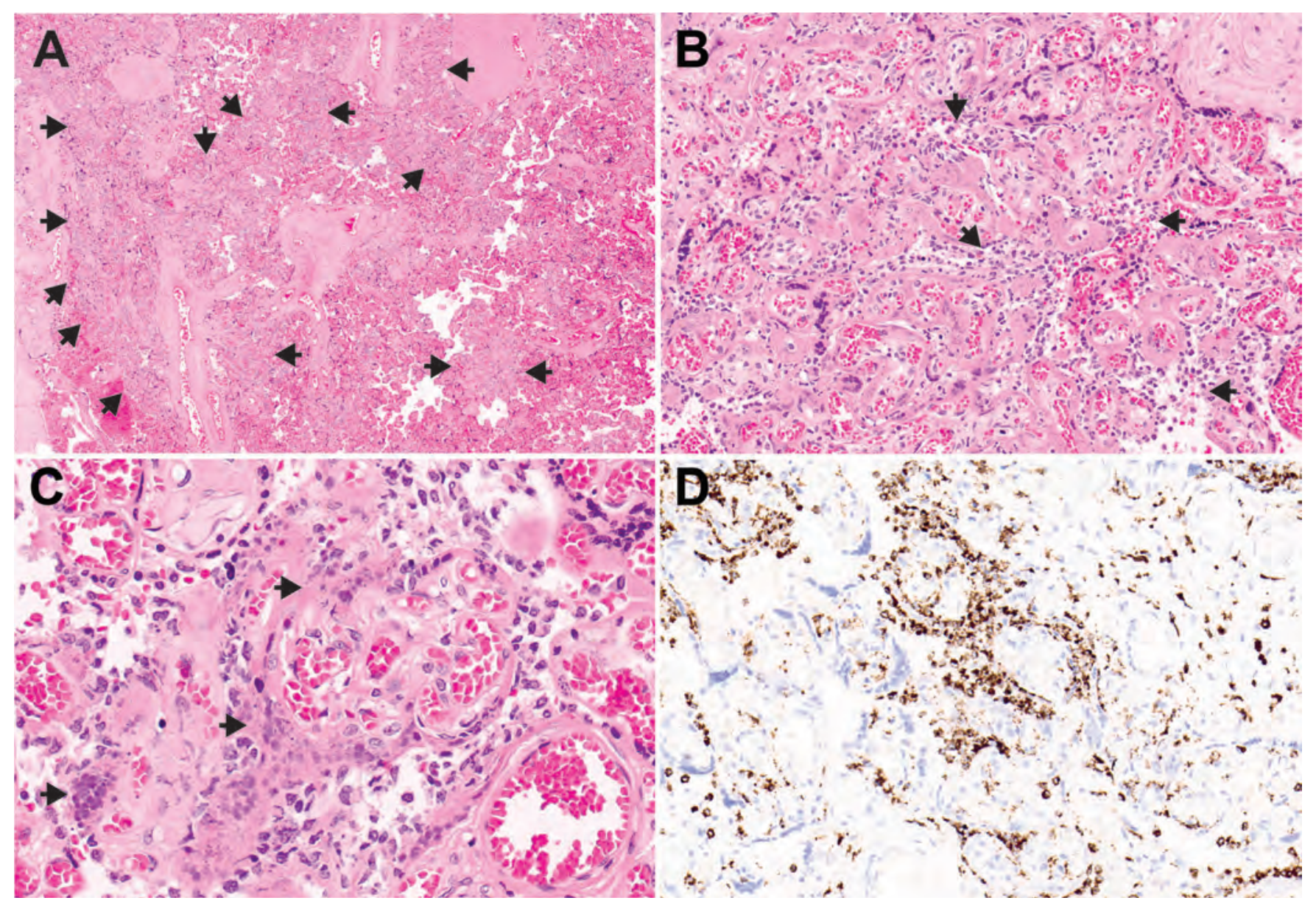

Figure 1: Placental photomicrographs. A) On low-power imaging, broad zones of cellular infiltrates are noted frequently but randomly throughout the section (arrows). The most normal area is present on the right side of the slide (hematoxylin-eosin, original magnification $\times 2$ ). B) Higherpower view shows infiltration of the intervillous space by chronic inflammatory cells (arrows). The chorionic villi are largely spared from the infiltration but, instead, show extensive early necrosis of the syncytiotrophoblast layer. Early perivillous fibrin deposition is also present (hematoxylin-eosin, original magnification $\times 20$ ). C) High-power view highlights the early infarction, with extensive smudginess and early fragmentation of the syncytiotrophoblast nuclei (arrows) (hematoxylin-eosin, original magnification $\times 40$ ). D) Immunostaining for the macrophage marker CD68 shows large numbers of the chronic inflammatory cells in the intervillous space, frequently encircling the chorionic villi (CD68 immunostain, original magnification $\times 20$ ).

(lowest glucose level $1.8 \mathrm{mmol} / \mathrm{L}$ ), which were managed with administration of dextrose gel and formula supplementation. Repeated episodes of hypoglycemia and feeding difficulties necessitated admission to the neonatal intensive care unit (NICU) at 37 hours of age for intravenous administration of glucose, thermoregulation and support for oral feeding. Treatment with ampicillin and tobramycin was started empirically (routine guideline for neonatal sepsis at our institution), which was discontinued 48 hours later after negative blood culture results. Within 24 hours of admission to the NICU, intravenous glucose treatment had been stopped, and the neonate maintained his temperature in an open cot and exhibited improved oral feeding. No radiologic investigations were needed. He was transferred back to his mother's room on the postnatal ward and was discharged home with his mother on day 4 after birth.

The neonate returned for routine assessment on day 7 . The clinical examination was unremarkable, showing no feeding difficulties, fever or cough. Repeat swabs for SARS-CoV-2 were taken from both the mother and the neonate (results in Appendix 1, Supplemental Table S1). A telephone follow-up on day 30 after birth indicated that the baby was thriving. At the time of writing, continued follow-up was in place through a community physician.

\section{Discussion}

Cases of suspected perinatal SARS-CoV-2 infection have been reported;2,3 however, in light of infrequent testing, the possibility of specimen contamination from infected maternal sites, the questionable validity of serologic testing, ${ }^{4}$ and a lack of standardized definitions for congenital, intrapartum and postpartum transmission, more evidence is needed to ascertain the route of transmission ${ }^{5}$ and to determine whether in utero transmission has in fact occurred.

Our case represents a probable case of congenital SARSCoV-2 infection in a liveborn neonate. Congenital infection is supported by the following findings: the neonate was not in contact with vaginal secretions; the membranes were intact before birth; and there was no skin-to-skin contact with the mother before collection of the first neonatal nasopharyngeal 
swab. The clinical phenotype of a late preterm neonate with SARS-CoV-2 infection is unknown. The clinical features of the baby in our case were compatible with the course of a late preterm neonate except for elevated liver enzyme levels. We have determined this case to be a probable ${ }^{6}$ case of congenital SARS-CoV-2 infection as opposed to a confirmed case because of lack of detection of the SARS-CoV-2 gene targets in the umbilical cord tissue as well as lack of availability of cord blood for SARS-CoV-2 testing.

Dong and colleagues ${ }^{7}$ and Zeng and colleagues ${ }^{4}$ identified the presence of IgM and IgG antibodies in neonates born to women with coronavirus disease 2019 (COVID-19), whereas, in another report, Zeng and colleagues ${ }^{2}$ identified SARS-CoV-2 RNA in nasopharyngeal swabs in 3 of 33 cases. Most investigators so far have not reported the presence of SARS-CoV-2 RNA in vaginal secretions, amniotic fluid or breast milk ${ }^{8}$ except for a recent case in which SARS-CoV-2 RNA was present in amniotic fluid. ${ }^{9}$ In our case, the mother's nasopharyngeal swab, breast milk and vaginal swab were positive for SARS-CoV-2 RNA. The potential for respiratory secretion contamination of breast milk cannot be ruled out but was minimized by breast hygiene and cleaning before specimen collection. The positive vaginal swab may reflect vaginal inoculation with stool. However, in the setting of positive placental swabs and placental parenchymal and chorion tissues, it is more likely consistent with shedding of the probably infected placental bed. SARS-CoV-2 infects host cells through angiotensinconverting enzyme 2 membrane-bound proteins, ${ }^{10}$ and angiotensin-converting enzyme 2 is expressed widely on the placenta. ${ }^{11,12}$ The temporal homogeneity of the findings and the presence of early infarction suggest diffuse involvement of the entire placenta, more consistent with primary viral infection than superinfection of a placenta already involved by chronic histiocytic intervillositis. Given that SARS-CoV-2 genes were not detected in the umbilical tissue, we suspect the possibility of a transamniotic route of infection via the placenta.

The usual diagnosis of congenital infection is made through compatible clinical features, and evidence of organism or antibodies in maternal blood, cord blood, amniotic fluid, placenta and neonate. Debate regarding transmission via blood or during the birth process is common. ${ }^{5}$ Thorough immediate testing is needed to understand the route of transmission of SARSCoV-2 infection.

In our case, maternal familial neutropenia and the associated immunocompromised state may have contributed to the widespread dissemination of the virus throughout body tissues and secretions. It is possible that the neutropenia in the neonate was secondary to inheritance of the maternal condition (confirmatory tests are pending), which may have altered his immunologic state, contributing to the acquisition of SARS-CoV-2 infection.

Congenital SARS-CoV-2 infection, with virus present in a neonate's nasopharynx at the time of birth, may occur, with a frequency not yet defined. All health care providers attending an infected woman's delivery and caring for the baby in the NICU should recognize this risk and use appropriate personal protective equipment to prevent droplet, contact and aerosol trans- mission if aerosol-generating procedures are considered. Neonates should be tested as soon as possible for SARS-CoV-2 RNA in cord blood, placental specimens and nasopharyngeal swabs, without waiting the 24 hours indicated in the current American Academy of Pediatrics guideline. ${ }^{13}$ This would establish the prevalence of SARS-CoV-2 in neonates of infected women and allow classification of those infected based on the process (in utero, intrapartum or postpartum) as opposed to the direction (vertical or horizontal) of transmission. ${ }^{6}$ This is also important for neonatal management and surveillance of the infant for delayed effects of transmission. Finally, it is important to note the timing, process and method of sample collection with early testing, so that intrapartum transmission (as opposed to a true congenital [in utero] infection) can be identified and proper precautions taken for health care workers. Having early results may also help with resource management while caring for the mother-newborn pair. Obtaining 2 consecutive negative SARSCoV-2 test results (swabs) for the neonate may allow caregivers to discontinue droplet and contact precautions; however, in some units, the baby will still be considered a contact of exposure for 14 days.

\section{References}

1. Vlachodimitropoulou Koumoutsea E, Vivanti AJ, Shehata N, et al. COVID-19 and acute coagulopathy in pregnancy. J Thromb Haemost 2020 Apr. 17. [Epub ahead of print]. doi: $10.1111 /$ jth.14856.

2. Zeng L, Xia S, Yuan W, et al. Neonatal early-onset infection with SARS-CoV-2 in 33 neonates born to mothers with COVID-19 in Wuhan, China. JAMA Pediatr 2020 Mar. 26. [Epub ahead of print]. doi: 10.1001/jamapediatrics.2020.0878.

3. Izamora MC, Paredes T, Caceres D, et al. Severe COVID-19 during pregnancy and possible vertical transmission. Am J Perinatol 2020 Apr. 18. [Epub ahead of print]. doi: 10.1055/s-0040-1710050.

4. Zeng $\mathrm{H}$, Xu C, Fan J, et al. Antibodies in infants born to mothers with COVID-19 pneumonia. JAMA 2020 Mar. 26. [Epub ahead of print]. doi: 10.1001/jama.2020. 4861.

5. Kimberlin DW, Stagno S. Can SARS-CoV-2 infection be acquired in utero?: more definitive evidence is needed. JAMA 2020 Mar. 26. [Epub ahead of print]. doi: 10.1001/jama.2020.4868.

6. Shah PS, Diambomba Y, Acharya G, et al. Classification system and case definition for SARS-CoV-2 infection in pregnant women, fetuses, and neonates. Acta Obstet Gynecol Scand 2020 Apr. 11. [Epub ahead of print]. doi: 10.1111/aogs .13870 .

7. Dong L, Tian J, He S, et al. Possible vertical transmission of SARS-CoV-2 from an infected mother to her newborn. JAMA 2020 Mar. 26. [Epub ahead of print]. doi: 10.1001/jama.2020.4621.

8. Chen H, Guo J, Wang C, et al. Clinical characteristics and intrauterine vertical transmission potential of COVID-19 infection in nine pregnant women: a retrospective review of medical records. Lancet 2020;395:809-15.

9. Zamaniyan M, Ebadi A, Aghajanpoor Mir S, et al. Preterm delivery in pregnant woman with critical COVID-19 pneumonia and vertical transmission. Prenat Diagn 2020 Apr. 17. [Epub ahead of print]. doi: 10.1002/pd.5713.

10. $\mathrm{Xu} \mathrm{H}$, Zhong L, Deng J, et al. High expression of ACE2 receptor of 2019-nCoV on the epithelial cells of oral mucosa. Int J Oral Sci 2020;12:8.

11. Levy A, Yagil Y, Bursztyn M, et al. ACE2 expression and activity are enhanced during pregnancy. Am J Physiol Regul Integr Comp Physiol 2008;295:R1953-61.

12. Li M, Chen L, Zhang J, et al. The SARS-CoV-2 receptor ACE2 expression of maternal-fetal interface and fetal organs by single-cell transcriptome study. PLoS One 2020;15:e0230295.

13. Puopolo KM, Hudak ML, Kimberlin DW, et al. Initial guidance: management of infants born to mothers with COVID-19. Washington: American Academy of Pediatrics Committee on Fetus and Newborn, Section on Neonatal Perinatal Medicine and Committee on Infectious Diseases; 2020 Apr. 2. Available: https://downloads.aap.org/AAP/PDF/COVID\%2019\%20Initial\%20Newborn\%20 Guidance.pdf (accessed 2020 Apr. 15). 
Competing interests: Susan Poutanen reports honoraria from Merck related to advisory boards and talks, honoraria from Verity, Cipher Pharmaceuticals and Paladin Labs related to advisory boards, partial conference travel reimbursement from COPAN Diagnostics, and research support from Accelerate Diagnostics and bioMérieux, all outside the submitted work. Ann Malinowski is a member of the Alexion post-pregnancy thrombotic microangiopathy advisory board and participated in a speaking engagement commisioned by Alexion on thrombotic microangiopathy in pregnancy. No other competing interests were declared.

This article has been peer reviewed.

The authors have obtained patient consent.

Affiliations: Departments of Pediatrics (Kirtsman, Diambomba, Shah), Obstetrics and Gynecology (Malinowski, Vlachodimitropoulou), and Pathology and Laboratory Medicine (Parks), Mount Sinai Hospital; Departments of Microbiology (Poutanen) and Medicine (Infectious Diseases) (Poutanen), University Health Network/Sinai Health; Depart- ments of Pediatrics (Kirtsman, Diambomba, Erdman, Morris, Shah), Laboratory Medicine and Pathobiology (Poutanen, Parks), Medicine (Poutanen), and Obstetrics and Gynecology (Malinowski, Vlachodimitropoulou), University of Toronto; Division of Infectious Diseases (Erdman, Morris), Department of Pediatrics, The Hospital for Sick Children, Toronto, Ont.

Contributors: Maksim Kirtsman and Prakesh Shah drafted the manuscript. All of the authors contributed equally to the conception and design of the work, revised the manuscript critically for important intellectual content, gave final approval of the version to be published and agreed to be accountable for all aspects of the work.

Acknowledgments: The authors thank Heather McDonald Kinkaid, Maternal-Infant Care Research Centre, Mount Sinai Hospital, Toronto, for editorial assistance in the preparation of the manuscript. They also thank the family for their consent to report this case.

Correspondence to: Prakesh Shah, prakeshkumar.shah@ sinaihealthsystem.ca 